\title{
Serious Adverse Reactions Caused by Counterfeit Drugs. A Clinical Case of Transient Global Amnesia Caused by Dietary Supplement Containing a High Dose of Sildenafil
}

Biondi $\mathbf{F}^{1^{*}}$, Savoia $\mathbf{G}^{1}$, Sasso $\mathbf{M}^{1}$, Lanza $\mathbf{A}^{1}$ and Pacifici $\mathbf{R}^{2}$

${ }^{1}$ Poison Control Center, HospitalA Cardarelli-Napoli, Italy 80059, Italy

${ }^{2}$ Drug Dipendence, Addiction and Doping department, Major Institute of Health, Rome, Italy

${ }^{*}$ Corresponding author: Biondi F, Hospital Pharmacist, AORN Antonio Cardarelli, Poison Control centre, Street Antonio Cardarelli 9, Naples, Italy 80059, Italy, Tel: 00393498488169; E-mail: federicabiondi@hotmail.com

Received date: May 24, 2016; Accepted date: June 06, 2016; Published date: June 13, 2016

Copyright: (C) 2016 Biondi F, et al. This is an open-access article distributed under the terms of the Creative Commons Attribution License, which permits unrestricted use, distribution, and reproduction in any medium, provided the original author and source are credited.

\begin{abstract}
On 25/11/2014 the patient VHG arrives at emergency department of Cardarelli Hospital in Naples following prolonged confusional state and total loss of memory in the last 24 hours. The episode is diagnosed as transient global amnesia (TSA). During the hospitalization the patient receives specialist visits that don't reveal any abnormalities. The patient reports that he assumed, a few hours before the onset of amnesia, a dietary supplement. The product named "Sex Bull", purchased online, it's indicated for the improvement of sexual performance both in men than in women and, in according to label, it doesn't contain any pharmacological active ingredient.

Poison Control Centre of Cardarelli Hospital provides to send a sample of tablets of "Sex Bull" to Superior Institute of Health (Rome) for a qualitative and quantitative determination of components. The analyses show the presence of Paracetamol, vitamin C, sugar and Sildenafil at the dosage of $100 \pm 1.5 \mathrm{mg}$ Sildenafil is a drug used in clinical practice for the treatment of erectile dysfunction and the sale of pharmaceutical products containing the active substance "Sildenafil" is subject to medical prescription.

In literature, are published several case-reports and a review reporting cases of TGA following a first administration of Sildenafil. In this case report, it's difficult to establish the causal link between the adverse drug reaction (ADR) and the consumption of the active substance Sildenafil, because "Sex Bull" it is a counterfeit drug.

The production and distribution of counterfeit drugs is not done according to Good Manufacturing Practice and Good Distribution Practice so the quality of pharmacological active ingredients isn't guaranteed. Because of these reasons it is not possible establishing any form of interaction between counterfeit products and other pharmaceutical therapies in progress or the ability of these drugs to induce serious ADR or aggravate a pre-existing medical condition.
\end{abstract}

Keywords: Adverse drug reaction; Counterfeit drugs; Sildenafil; Transient global amnesia

\section{Introduction}

The use of counterfeit drugs can cause serious damage to human health. A counterfeit medicine is one which is deliberately and fraudulently mislabelled with respect to identity and/or source. Counterfeiting can apply to both branded and generic products and counterfeit products may include products with the correct ingredients, wrong or toxic ingredients, without active ingredients, with insufficient quantity of active ingredients or with fake packaging.

The counterfeiting of any product is a crime that is occurring worldwide and It has increased substantially in recent years [1]. In this case report a serious adverse drug reaction (ADR) occurred in patient following the assumption of a counterfeit drug, purchased online, containing the pharmacological active ingredient Sildenafil.

\section{Clinical Case}

On 25/11/2014 the patient VHG, Colombian male resident in Italy, arrives at emergency department of Cardarelli Hospital located in Naples.

The patient, 46 years old, reports a prolonged confusional state that resulted in total loss of memory in the last 24 hours. The episode is diagnosed by doctors of emergency department as Transient Global Amnesia (TSA), which is a form of retrograde amnesia characterized by sudden onset and lasting less than 24 hours. The patient is able to execute complex orders; He preserves the personal identity, motor, sensory and reflex function.

The patient reports not to use drugs and not to be affected by noteworthy pathologies. He denies having consumed any alcohol, smoke and/or drugs in the hours before the incident. Finally he reports that he assumed, a few hours before the onset of amnesia, a dietary supplement. The product named "Sex Bull" (Sex Bull 15 tablets Potencia sexual sexo), can be purchased online. According to the label the product is indicated for the improvement of sexual performance 
Citation: Biondi F, Savoia G, Sasso M, Lanza A, Pacifici R (2016) Serious Adverse Reactions Caused by Counterfeit Drugs. A Clinical Case of Transient Global Amnesia Caused by Dietary Supplement Containing a High Dose of Sildenafil. J Pharmacovigil 4: 212. doi: $10.4172 / 2329-6887.1000212$

Page 2 of 2

both in men than in women and it contains only natural extracts of fruit of palm, a tropical fruit named Borojo, vitamins and minerals.

\section{The patient is subjected to specialist visits and routine checks}

Neurological examination does not reveal sensory-motor deficits in place. The patient appears alert, cooperative, well oriented in space and time. The patient is eupneic and oxygen saturation is $98 \%$. Blood pressure is $130 / 80 \mathrm{mmHg}$ and heart rate is 82 beats per minute.

Neurological examination on the next day reveals a possible family history of epilepsy and probable use of stimulants. On the same day the Electroencephalogram is negative for acute cases, while the results provided by the TAC don't indicate densitometric alterations of brain nerve tissue.

Cardiologic examination reveals that tones are valid and rhythmic, and electrocardiographic abnormalities don't emerge.

The toxicological examination of the blood is negative for all tested substances (barbiturates, cocaine, cannabis, MDMA, methamphetamine, tricyclic antidepressants, morphine).

The Valproic Acid dose is $3.2 \mu \mathrm{g} / \mathrm{mL}$ (range between 50 and 100), Digoxin $0.34 \mathrm{ng} / \mathrm{mL}$ (therapeutic range between 0.8 and 2.0), Phenytoin $0.2 \mu \mathrm{g} / \mathrm{mL}$ (range between 10 and 20) Phenobarbital 0.2 $\mu \mathrm{g} / \mathrm{mL}$ (therapeutic range between 15 and 40 ). This measures indicate a recent assumption of reported drugs, but the patient denies it.

The patient is discharged on 27.11, and he's asked, once He would have reach his domicile to send to the Poison Control centre located at Cardarelli Hospital a sample of tablets Sex Bull.

Poison Control Centre, received the sample, and sends it to Superior Institute of Health (Rome) for a qualitative and quantitative determination of components of the product.

\section{Results}

The Sex Bull tablets were analyzed using such as analytical technique gas chromatography/mass spectrometry (GC/MS) .The tablets Sex bull typified by triangular shape and light brown color have a weight of $298 \pm 1 \mathrm{mg}$. Analysis on sample was performed for the determination of drugs and psychotropic substances and for researching biologically or pharmacologically active substances.

The analyses show the presence of Paracetamol, Vitamine C, sugar, Sildenafil. In particular the concentration of Paracetamol detected in the tablets is equal to $62.0 \pm 2 \mathrm{mg}$ and that of Sildenafil was $100 \pm 1.5$ mg.

\section{Discussion and Conclusion}

Sildenafil is a drug used in clinical practice for the treatment of erectile dysfunction. The drug inhibiting phosphodiesterase type 5 (PDE-5), enzyme located in the cavernous body, causes an accumulation of cyclic guanosine monophosphate (cGMP) and smooth muscle relaxation. This allows the blood flow and causes an erection.

The sale of pharmaceutical products containing the active substance "Sildenafil" is subject to medical prescription.
The dosage of Sildenafil in the tablets of "Sex Bull" is found to be the maximum present in marketed drugs.

Among the medically important adverse reactions reported to have an incidence greater than placebo in the context of controlled clinical studies and medically important adverse reactions reported during post-marketing surveillance of the main preparations available containing Sildenafil, It's not reported any form of amnesia. In literature, however, are published several case-reports [2] and also a review [3] who report cases of TGA following a first administration of Sildenafil. Furthermore in FDA-AERS database, 16\% (44/274) of adverse reactions to Sildenafil, are reported cases of amnesia or loss of consciousness.

In this case report, it's difficult to establish the causal link between the adverse reaction and the consumption of the active substance Sildenafil, because it's contained in a counterfeit drug.

Counterfeit drugs can cause serious adverse reactions due to their poor quality. The production, in fact, even if made with non-toxic ingredients, is not done according to Good Manufacturing Practice, international standards that govern and document every operation, every activity and every aspect during the process of production of a drug. Furthermore the traceability of a counterfeit product is not guaranteed because they are not complied with Good Distribution Practice, rules ensuring that the quality and integrity of the medication remain throughout the distribution chain, from the manufacturer to the patient.

Because of these reasons It's not possible establishing the ability of Sildenafil contained in "Sex Bull" to induce serious ADR, to determinate any form of interaction with other pharmaceutical therapies in progress (in this clinical case the pharmacological interactions between Sildenafil and Valproic Acid, Digoxin, Phenytoin and Phenobarbital), nor the ability to aggravate a pre-existing medical condition.

Europe work hard in combating pharmaceutical counterfeiting adopting the DIRECTIVE 2011/62/EU on the Community code relating to medicinal products for human use, in order to prevent the entry of falsified medicines into the legal supply chain. Counterfeiting is a global problem that requires effective international coordination and cooperation, in order to ensure greater effectiveness of antifalsification strategies, in particular in the matter of sale of counterfeit products on Internet.

This form of intervention is crucial in ensuring a high level of public health, protecting the population from severe reactions related to pharmaceutical products whose labelling does not conform to the actual quantitative and qualitative composition and for which the origin of the raw materials, methods of preparation, storage and distribution are not in compliance with international standards.

\section{References}

1. World Health Organization (1992) Counterfeit drugs: report of a joint WHO/IFPMA workshop.

2. Shihman B, Auriel E, Bornstien NM (2006) Two cases of transient global amnesia (TGA) following Sildenafil use. Harefuah 145: 656-657.

3. Farooq MU, Naravetla B, Moore PW, Majid A, Gupta R, et al. (2008) Role of Sildenafil in neurological disorder. Clin Neuropharmacol 31:353-362. 